\title{
Comparative study of the therapeutic efficacy of autologous platelet-rich plasma and honey in healing skin wounds in sheep
}

\author{
Daikh Badis ${ }^{1,2}$ and Deffa Ouafa ${ }^{1,3}$ (i) \\ 1. Department of Biology of Organisms, University of Batna 2, Batna, Algeria; 2. Biotechnology's Laboratory of the \\ Bioactive Molecules and the Cellular Physiopathology, University of Batna 2, Batna, Algeria; 3. Laboratory of Biology and \\ Environment, Faculty of Nature and Life Sciences, University of Mentouri Brothers, Constantine, Algeria. \\ Corresponding author: Daikh Badis, e-mail: badis.daikh@univ-batna2.dz \\ Co-author: DO: o.deffa@univ-batna2.dz \\ Received: 07-04-2021, Accepted: 16-07-2021, Published online: 23-08-2021
}

doi: www.doi.org/10.14202/vetworld.2021.2170-2177 How to cite this article: Badis D, Ouafa D (2021) Comparative study of the therapeutic efficacy of autologous platelet-rich plasma and honey in healing skin wounds in sheep, Veterinary World, 14(8): 2170-2177.

\begin{abstract}
Background and Aim: This investigation is the continuation of a published preliminary study examining the therapeutic efficacy of platelet-rich plasma (PRP) as a topical treatment for skin wounds in sheep. The study aimed to compare the healing effects of autologous PRP with that of natural honey.

Materials and Methods: This study involved nine clinically healthy male sheep. After sterile skin preparation, fullthickness longitudinal incision wounds were created on the backs of each animal. The animals were randomly divided into three groups of three sheep each. In Group I, the wounds were treated with PRP; in Group II, the wounds were treated with honey; and in Group III, the wounds were treated with saline solution. The different treatments were administered topically every 3 days. Healing was assessed by a semi-quantitative histopathological study from biopsies taken on the $3^{\text {rd }}, 7^{\text {th }}, 14^{\text {th }}$, $21^{\text {st }}$, and $28^{\text {th }}$ days of healing. The data obtained were compared using the non-parametric Mann-Whitney U-test, and $p<0.05$ and 0.01 were used to determine the level of significance of the recorded differences.
\end{abstract}

Results: Semi-quantitative histopathological evaluation showed significant differences in the progression of wound healing between the three study groups. Recorded data showed that PRP may reduce inflammation during the first 3 days after the incision. Moreover, the synthesis and organization of collagen fibers were significantly improved in the group treated with PRP compared with those in the group treated with honey.

Conclusion: PRP offers a promising therapeutic option for healing skin wounds in sheep compared with honey.

Keywords: honey, platelet-rich plasma, sheep, skin, wound healing.

\section{Introduction}

The skin forms a mechanically flexible barrier protecting higher organisms from various traumas and infections [1]. Restoring the structural integrity of the skin depends on the interplay of healing stages that begin immediately after the trauma. Successful healing involves an orderly orchestration of several processes: Cell migration, proliferation, and differentiation $[2,3]$. These empirical stages include inflammation, reepithelization, granulation tissue formation, wound contraction, and tissue remodeling. The last step corresponds to the formation of the extracellular matrix (ECM), which requires a sequence of events at the molecular, cellular, and tissue levels, including cell-cell and cell-matrix interactions $[4,5]$. Although fibroblasts and keratinocytes play a key role in wound healing, at the molecular level, other elements, such as growth

Copyright: Badis and Ouafa. Open Access. This article is distributed under the terms of the Creative Commons Attribution 4.0 International License (http://creativecommons.org/licenses/ by/4.0/), which permits unrestricted use, distribution, and reproduction in any medium, provided you give appropriate credit to the original author(s) and the source, provide a link to the Creative Commons license, and indicate if changes were made. The Creative Commons Public Domain Dedication waiver (http:// creativecommons.org/publicdomain/zero/1.0/) applies to the data made available in this article, unless otherwise stated. factors, cytokines and their receptors, and matrix molecules, are essential [4].

Wound care during the healing process is particularly important to prevent complications, such as infections and keloids, which can compromise the esthetic aspect of healing [5]. One of the goals of modern medical science is to try to heal a wound in a shorter time with fewer side effects. In this context, many studies have been published, and various therapeutic agents that can affect and promote wound healing were proposed. Dohan et al. [6] have considered a new therapeutic approach for wound healing using autologous platelet concentrates (i.e., platelet-rich plasma [PRP]) derived from fibrin glue technology in the 1990s. Several publications on its effectiveness have been reported, but it remains widely controversial because of the absence of a consensus to standardize the protocol for its preparation [6,7]. Most animal experiments have highlighted that PRP accelerates wound healing and stimulates cell proliferation and granulation tissue formation. In contrast, for thousands of years, honey was known for its therapeutic wound healing properties. Long used in the $20^{\text {th }}$ century, it was gradually abandoned after World War II in favor of more modern, more innovative products, such as asiaticoside. Honey is recognized for its antibacterial 
activity and promotes wound healing through different mechanisms. It stimulates the proliferation of fibroblasts, improves the formation of granulation tissue, and decreases the activity of collagenase.

The increased interest in complementary therapies for skin healing, such as the use of synthetic or natural remedies, has led to a deep investigation of these products, but few studies have compared their modalities of action $[8,9,10]$. In this context, we conducted this study to evaluate the effectiveness of PRP and honey in healing skin wounds in sheep and compare their biological effects.

\section{Materials and Methods}

\section{Ethical approval}

This study was approved by the Ethics Committee of the Institute of Agronomic and Veterinary Sciences of the University of BATNA 1 - Algeria.

\section{Study period and location}

The study was conducted from March to May 2019, on sheep belonging to the University of Batna 1, Algeria. During the experiment, all surgical maneuvers were performed in a laboratory at an ambient temperature of $25^{\circ} \mathrm{C}$.

\section{Experimental animals}

Nine healthy adult male sheep weighing $20-25 \mathrm{~kg}$ were used in this study. These animals were bred in the animal house of the Institute of Veterinary and Agronomic Sciences, University of Batna 1. All these animals had free access to water and an ordinary diet (i.e., straw and barley). One month before surgery, all sheep were dewormed using ivermectin at a dose of $0.2 \mathrm{~mL} / \mathrm{kg}$ administered subcutaneously.

\section{Preparation of PRP and honey}

The steps for preparing the PRP were performed according to a double centrifugation protocol proposed by Carneiro et al. [11] and modified by Daikh and Benoune [7]. Then, $20 \mathrm{~mL}$ whole blood was taken by a septic puncture of the jugular vein of each sheep. Then, the collected blood was dispensed into $5 \mathrm{~mL}$ tubes containing citrate dextrose acid. The speed of the first centrifugation was set at $1800 \mathrm{rpm}$ for $8 \mathrm{~min}$, and the second centrifugation was performed at $1000 \mathrm{rpm}$ for $8 \mathrm{~min}$. The total amount of PRP collected was $2.5 \mathrm{~mL}$. All steps were performed at an ambient temperature of $22^{\circ} \mathrm{C}$. For honey, it was harvested from the nectar of jujube plants in late spring in the mountainous region of Arris in Algeria. For isolating impurities, honey was passed through a Whatman $0.5 \mathrm{~mm}$ filter at $25-30^{\circ} \mathrm{C}$, then transferred to a dark lid dish, and used in the research laboratory.

\section{The count of platelets and realization of smears}

The platelet count was taken using a hemocytometer (Neubauer cell improved). Smears of whole blood and PRP were stained with May-Grünwald-Giemsa stain on each count to isolate the animals affected by hematological diseases and assess the richness of thrombocytes in the PRP.

\section{Experimental grouping of animals}

The animals were randomized into three groups consisting of three sheep in each group. Various treatments were administered topically once on 3-day intervals. PRP was prepared on each administration and activated by adding calcium chloride $(0.1 \mathrm{~mL} \mathrm{CaCl}$, to each $1 \mathrm{~mL}$ PRP) immediately before its application [12]. For natural honey, $1 \mathrm{~g}$ was used directly on the wound surface.

- Group I: Animals treated with PRP

- Group II: Animals treated with honey

Group III: Animals treated with saline solution ( $\mathrm{NaCl} 09 \%)$.

\section{Realization of skin wounds}

Before all surgical interventions, the animals were first tranquilized with acepromazine at a dose of $0.1 \mathrm{mg} / \mathrm{kg}$ intramuscularly. Then, the skin was shaved and disinfected by applying an iodine solution of povidone (dermal betadine 10\%). On the back of each animal, two full-thickness longitudinal incision wounds ( $7 \mathrm{~cm}$ in length) were created on each lateral side near the vertebral line [13]. The incision was made under the effect of local anesthesia (lidocaine hydrochloride $02 \%$ ), induced by subcutaneous infiltration at a flow rate of $1 \mathrm{~mL} / 1 \mathrm{~cm}^{3}$ [14]. Then, all wounds were sutured using a non-absorbable thread (STERIM*, T-30 mm-4/8). All rules of asepsis were strictly observed.

\section{Clinical follow-up}

Every day, all laboratory animals were examined (in terms of animal behavior, body temperature, and cardiorespiratory activity, among others). Within the wounds, a daily macroscopic follow-up was performed throughout the experimentation period.

\section{Follow-up of healing: Semi-quantitative histopatho- logical study}

Skin samples using a biopsy punch $(4 \mathrm{~mm}$ BP-40F) from the lesion incision sites were taken on the $3^{\text {rd }}, 7^{\text {th }}, 14^{\text {th }}, 21^{\text {st }}$, and $28^{\text {th }}$ days after surgery. The samples were processed by routine histological procedures: First, they were fixed with buffered formalin, then embedded in paraffin solution, and cross-sectioned using a microtome into $4 \mu \mathrm{m}$ thin sections. The tissue sections were stained with hematoxylin and eosin and examined for possible histopathological changes. The histopathological scores established by Vidinsky et al. [15] and Kilík et al. [16] were used in this study (presented in Table-1 by codes from 0 to 3).

\section{Statistical analysis}

For each variable in the study, a descriptive statistical analysis was performed. Mean values \pm standard deviations were calculated. The data obtained from the semi-quantitative evaluation of the histopathological parameters were compared using the non-parametric Mann-Whitney U-test. All statistical analyses were performed using the Statistical Package for the Social Sciences, version 23.0. $p<0.05$ and 0.01 were used to determine the level of significance of the recorded differences. 


\section{Results}

\section{Clinical follow-up}

After the surgical incisions were made, the animals remained healthy without clinical evidence of infection. All animals well tolerated the anesthesia and surgical procedure and did not appear to be affected by the presence of the wounds on their backs.

\section{PRP}

The mean platelet count is much higher in PRP $\left(1463.2 \pm 95.22 \times 10^{3} / \mu \mathrm{L}\right)$ than in whole blood $\left(466.46 \pm 80.22 \times 10^{3} / \mu \mathrm{L}\right)$. It is approximately 3 -fold higher than that in whole blood (Figure-1).

\section{Histopathological follow-up}

Semi-quantitative histopathological evaluation (Table-2) showed differences in the progression of healing in the three study groups.

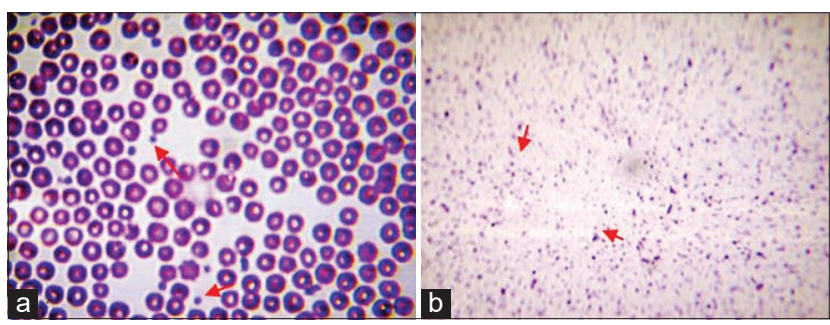

Figure-1: Smears showing thrombocytes (arrows) of whole blood (a), platelet-rich plasma (b). Stain: May-Grunwald-Giemsa (M.G.Gx100).
Three days after surgery, our results showed a significant difference in favor of PMNL, recorded in the group of animals treated with PRP $(2.16 \pm 0.57)$.

For the other groups, only an accidental infiltration of a few leukocytes in all wounds was observed but without statistical relevance (Figure-2a). Regarding reepithelialization, after $48 \mathrm{~h}$, a layer of epithelium thickened at the free edge of the wound was observed in all groups (Figure-3). In contrast, new blood vessels and newly formed collagen deposits were observed in the groups treated with PRP and honey $(0.75 \pm 0.45$ and $0.33 \pm 0.49$, respectively) compared with the control group ( $0 \pm 0$ and $0 \pm 0$, respectively). For these parameters, our statistical analysis revealed no significant difference.

Seven days after surgery, the inflammatory infiltration phase was completed in all wounds, but without statistical relevance. Histological examination after 7 days revealed the formation of an almost continuous epithelial layer on the incision surfaces in the group of animals treated with PRP with a significant difference (Figure-2b) compared with the control group $(1.66 \pm 0.49 *$ vs. $0.83 \pm 0.57$, respectively). Concerning fibroplasia and newly formed blood vessels, these parameters were slightly accelerated in the groups treated with PRP and honey (Figures-4a and 4b) in comparison with the control group (Figure-4c). The number of macrophages

Table-1: Significance of the different histopathological scores of the semi-quantitative histological evaluation of skin wound healing.

\begin{tabular}{lllllll}
\hline Score & Reepithelization step & PMNL & Macrophages & Fibroblasts & $\begin{array}{l}\text { New blood } \\
\text { vessels }\end{array}$ & New collagen \\
\hline 0 & Thickening of cut edges & Absence & Absence & Absence & Absence & Absence \\
1 & Migration of épithélial cells & Minimum & Minimum & Minimum & Minimum & Minimum \\
2 & Bridging of the incision & Moderate & Moderate & Moderate & Moderate & Moderate \\
3 & Complete régeneration & Marked & Marked & Marked & Marked & Marked \\
\hline
\end{tabular}

*Polymorphonuclear leukocytes. PMNLs=Polymorphonuclear leukocytes

Table-2: Results of the semi-quantitative analysis of the histopathological evaluation of the healing of skin wounds. Each calculated parameter was presented by its mean and standard deviation (mean \pm SD).

\begin{tabular}{|c|c|c|c|c|c|c|c|}
\hline Day & Group & $\begin{array}{c}\text { Reepithelization } \\
\text { step }\end{array}$ & PMNL & Macrophages & Fibroblasts & $\begin{array}{l}\text { New blood } \\
\text { vessels }\end{array}$ & New collagen \\
\hline \multirow[t]{3}{*}{ Day 3} & I & $0.7 \pm 0.48$ & $2.16 \pm 0.57 *$ & $1.25 \pm 0.45$ & $0.83 \pm 0.71$ & $0.75 \pm 0.45$ & $0.33 \pm 0.49$ \\
\hline & II & $0.5 \pm 0.52$ & $1.41 \pm 0.66$ & $1.41 \pm 0.51$ & $0.66 \pm 0.49$ & $0.58 \pm 0.51$ & $0.16 \pm 0.38$ \\
\hline & III & $0.2 \pm 0.42$ & $1.25 \pm 0.45$ & $1.58 \pm 0.51$ & $0.33 \pm 0.49$ & $0 \pm 0$ & $0 \pm 0$ \\
\hline \multirow[t]{3}{*}{ Day 7} & $\mathrm{I}$ & $1.66 \pm 0.49 *$ & $2.5 \pm 0.67$ & $1.08 \pm 0.28$ & $1.91 \pm 0.66 *$ & $1.41 \pm 0.51$ & $1.58 \pm 0.51$ \\
\hline & II & $1.41 \pm 0.51$ & $2.16 \pm 0.71$ & $1.5 \pm 0.52$ & $1.58 \pm 0.66$ & $1.16 \pm 0.38$ & $1.41 \pm 0.51$ \\
\hline & III & $0.83 \pm 0.57$ & $1.66 \pm 0.77$ & $1.66 \pm 0.42 *$ & $1.08 \pm 0.79$ & $1.25 \pm 0.45$ & $1.16 \pm 0.57$ \\
\hline \multirow[t]{3}{*}{ Day 14} & I & $2.0 \pm 0.6$ & $0.58 \pm 0.66$ & $1.25 \pm 0.45$ & $2.75 \pm 0.45 *$ & $2.90 \pm 0.31$ & $2.75 \pm 0.45 * *$ \\
\hline & II & $1.66 \pm 0.65$ & $0.83 \pm 0.93$ & $1.41 \pm 0.51$ & $2.5 \pm 0.52$ & $2.60 \pm 0.51$ & $2.66 \pm 0.49 *$ \\
\hline & III & $1.58 \pm 0.51$ & $1.08 \pm 1.44$ & $1.5 \pm 0.51$ & $2.16 \pm 0.57$ & $2.50 \pm 0.52$ & $2.0 \pm 0.60$ \\
\hline \multirow[t]{3}{*}{ Day 21} & I & $2.75 \pm 0.45 *$ & $0.16 \pm 0.38$ & $0.58 \pm 0.51$ & $3.0 \pm 0$ & $3.0 \pm 0$ & $3.0 \pm 0$ \\
\hline & II & $2.25 \pm 0.62 *$ & $0.33 \pm 0.49$ & $0.83 \pm 0.38$ & $2.85 \pm 0.38$ & $2.87 \pm 0.35$ & $2.75 \pm 0.45$ \\
\hline & III & $1.91 \pm 0.79$ & $0.58 \pm 0.66$ & $1.00 \pm 0.42$ & $2.66 \pm 0.49$ & $2.44 \pm 0.52$ & $2.5 \pm 0.52$ \\
\hline \multirow[t]{3}{*}{ Day 28} & I & $3 \pm 0$ & $0.0 \pm 0$ & $0.0 \pm 0$ & $1.83 \pm 0.38$ & $1.9 \pm 0.31$ & $3.0 \pm 0$ \\
\hline & II & $2.75 \pm 0.45$ & $0.0 \pm 0$ & $0.0 \pm 0$ & $1.66 \pm 0.49$ & $2.33 \pm 0.50$ & $3.0 \pm 0$ \\
\hline & III & $2.5 \pm 0.52$ & $0.33 \pm 0.49$ & $0.5 \pm 0.67$ & $1.75 \pm 0.75$ & $2.37 \pm 0.51$ & $2.72 \pm 0.46$ \\
\hline
\end{tabular}

PMNL=Polymorphonuclear leukocytes 


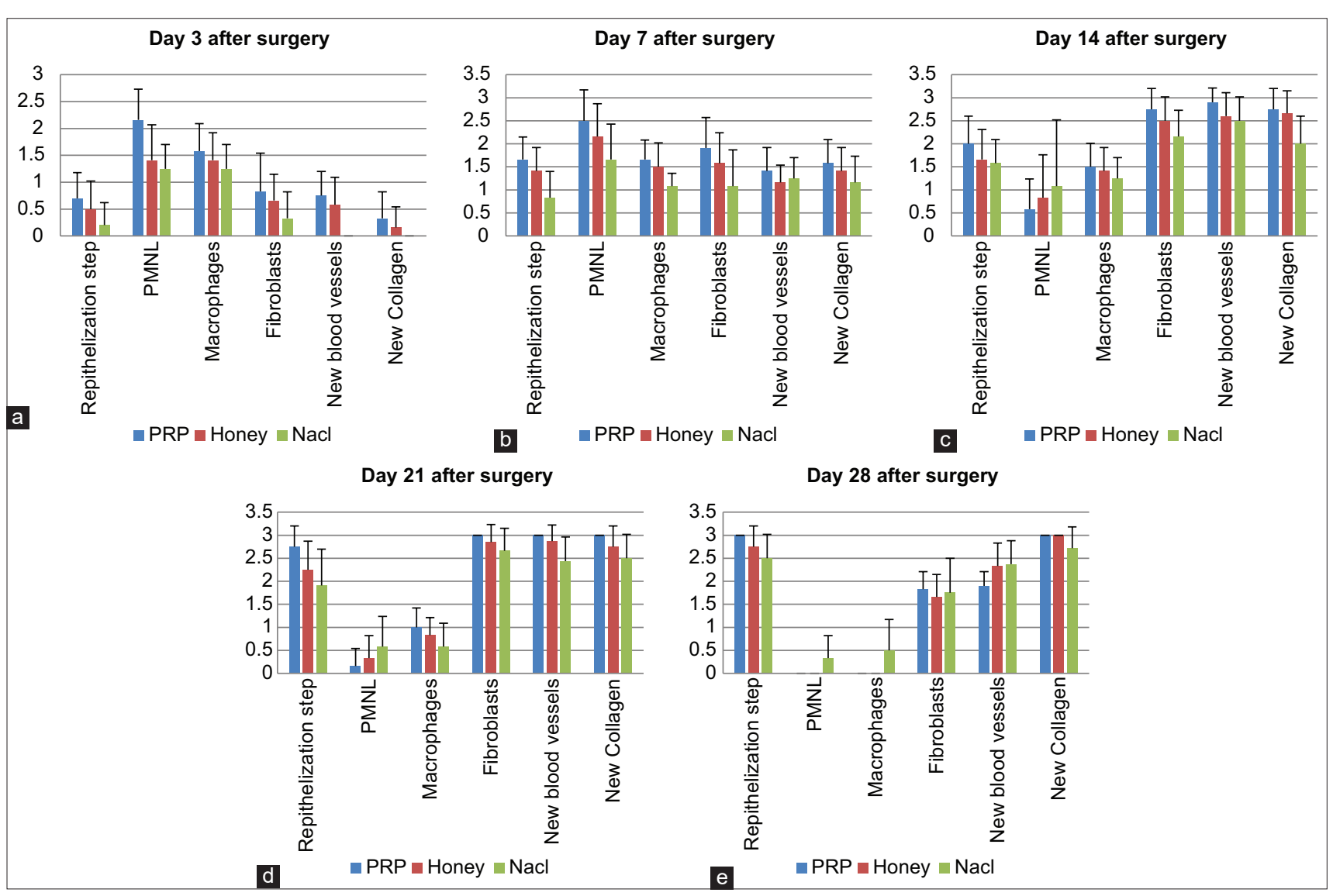

Figure-2: Results of the semi-quantitative analysis of the histopathological scores in the different groups of animals. (a) Results of the semi-quantitative analysis after 3 days, (b) after 7 days of healing, (c) after 14 days, (d) after 21 days. and (e) after 28 days of healing (data are presented as mean $\pm S D ; * p<0.05, * * p<0.01$ ).

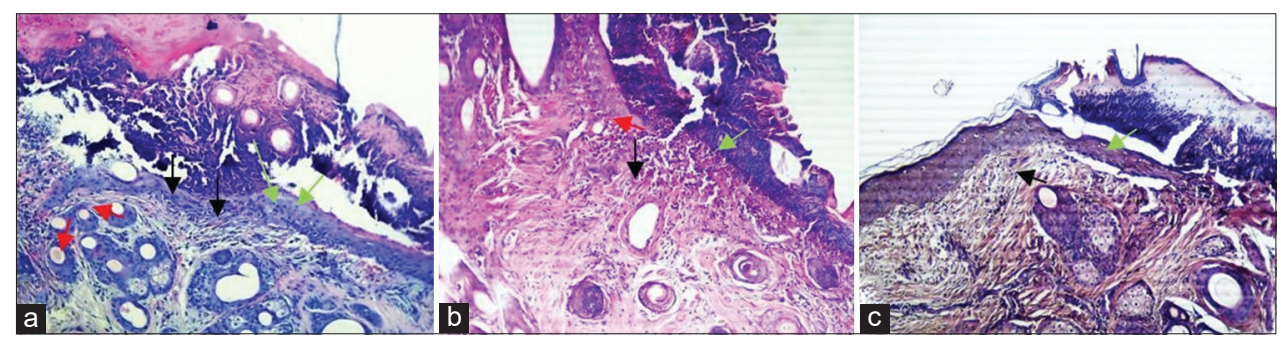

Figure-3: Microscopic view of the different histological aspects of healing, from skin biopsies, performed on the $3^{\text {rd }}$ day after surgery (magnification is $100 \times$ ). Green arrow (reepithelialization), red arrow (neovascularization), black arrow (inflammatory cells). In the group of animals treated with platelet-rich plasma (PRP) (a), the granulation tissue is already developing, with moderate angiogenesis and significant leukocyte infiltration compared to the animals in the group treated with honey (b). Reepithelialization is marked in all wounds, but to varying degrees. The epithelium is hyperplastic in wounds treated with PRP compared to control wounds (c), treated with saline solution. The wound edges appeared to be covered with blood coagulum in all wounds, particularly in the control wounds.
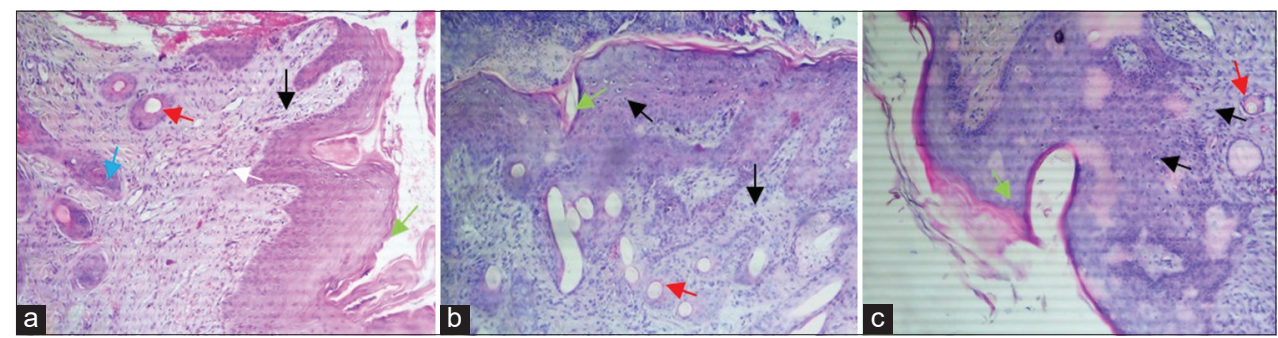

Figure-4: Microscopic view of the different histological aspects of healing, from skin biopsies, taken on the $7^{\text {th }}$ day after surgery (magnification is $100 \times$ ). Green arrow (reepithelialization), red arrow (neovascularization), black arrow (inflammatory cells), blue arrow (macrophages), white arrow (fibroblasts), brown arrow (collagen fibers). In the wounds of the group of animals treated with platelet-rich plasma (a), the epithelial layer showed hypertrophy, with much more differentiated keratinocytes and development of stratum spinosum and stratum granulosum, compared to wounds treated with honey (b) and saline solution (c), respectively. 
and fibroblasts was significantly higher in the PRPtreated group.

Fourteen days after surgery, the synthesis and organization of collagen fibers were significantly improved in the groups treated with PRP and honey (Figure-5a). At an equal rank, the statistical treatment of the results obtained (Figure-2c) revealed a significant difference in favor of wounds treated with honey and a highly significant difference in favor of wounds treated with PRP $\left(2.66 \pm 0.49^{*}\right.$ and $2.75 \pm 0.45^{* *}$, respectively).

Twenty-one days after surgery, reepithelization, fibroplasia, neoangiogenesis, and formation of new bands of collagen were observed and reached their maximum in wounds treated with PRP (Figure-2d). Reepithelialization was significantly improved with completely united tissues in wounds treated with PRP and honey $(2.75 \pm 0.45$ and $2.25 \pm 0.62$, respectively) compared with that in the control group $(1.91 \pm 0.79)$. In contrast, no significant difference in reepithelialization was recorded between wounds treated with PRP and honey (Figure-6).

Twenty-eight days after surgery, all wounds healed. The healing process is especially accelerated in wounds treated with PRP (Figure-2e), characterized by complete reepithelialization with perfect keratinization and reappearance of hair follicles. The collagen fiscal densely filled the wound bed with good reorientation. Delayed poor healing was observed in control wounds with pronounced fibrosis (Figure-6f).

\section{Discussion}

Currently, in the field of regenerative medicine the use of emerging cells therapies, such as PRP, offered a hopeful challenge to clinicians and patients
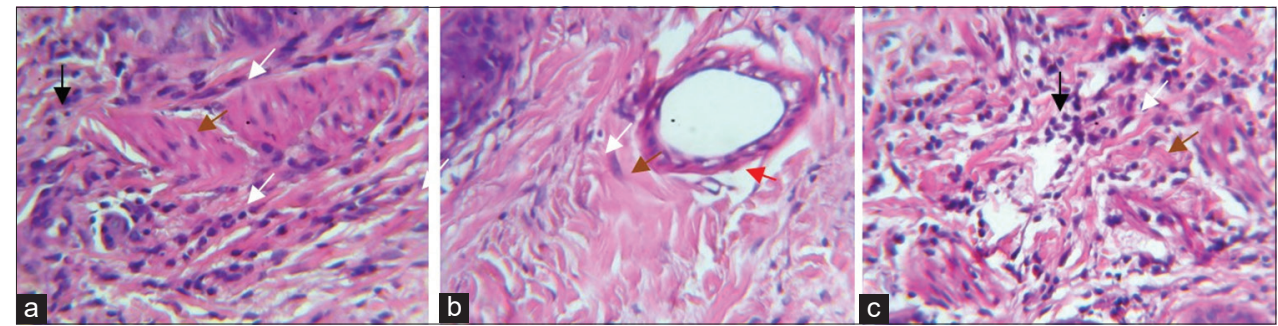

Figure-5: Hematoxylin and eosin stains in wound tissue (a-c) on day 14 after surgery. Black arrow (inflammatory cells), white arrow (fibroblasts), brown arrow (collagen fibers) (magnification is $400 \times$ ). In the dermis of wounds treated with platelet-rich plasma (PRP) (a), collagen fibers much denser, tight, and organized, with an armada of fibroblasts sparse over the entire injured surface. In the dermis of wounds treated with honey (b), the deposition of collagen fibers was less pronounced in comparison with wounds of the PRP group. The samples from the wounds of group (c), treated with the saline solution, showed a dermis strewn with fine collagen fibers and poorly oriented.

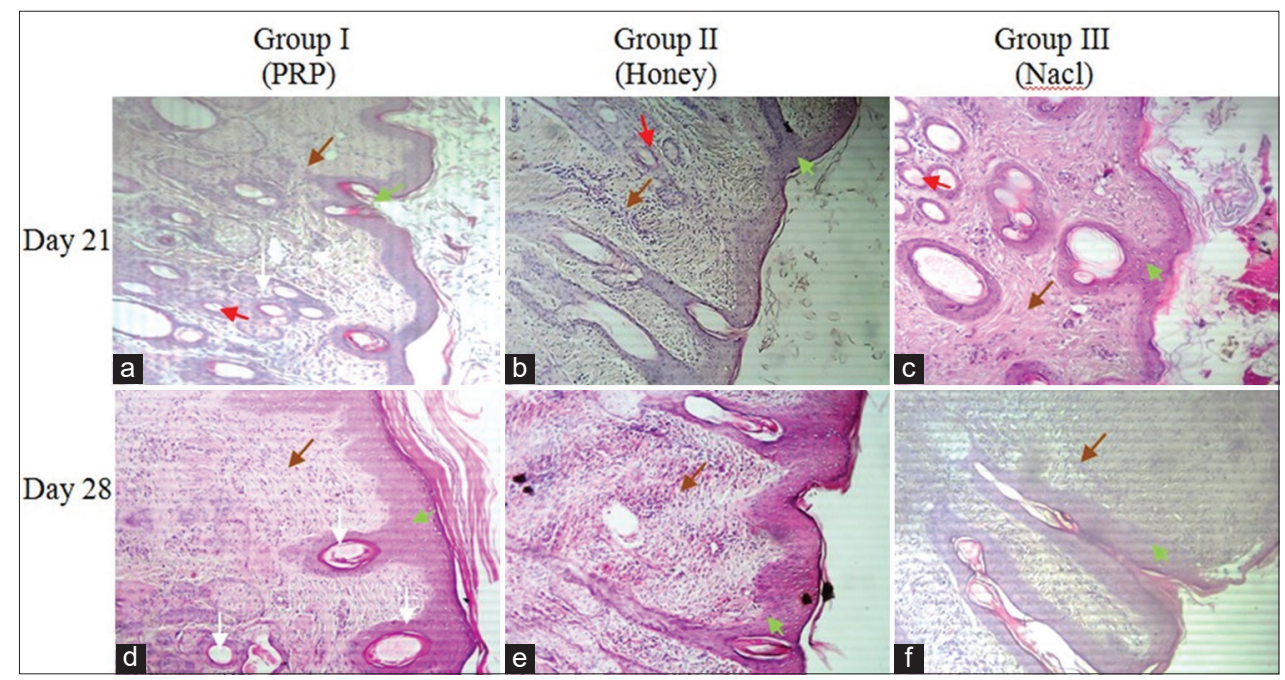

Figure-6: Photomicrographs of various histological appearances (cross section) from skin biopsies taken on the $21^{\text {th }}$ (a-c) and $28^{\text {th }}(\mathrm{d}-\mathrm{c}$ ) days after surgery (magnification is $100 \times)$. Green arrow (reepithelialization), red arrow (neovascularization), black arrow (inflammatory cells), white arrow (hair follicle), brown arrow (collagen fibers). On the $21^{\text {th }}$ day of the healing process, all the wounds healed $(a-c)$, with significant variations depending on the different treatments administered. In wounds treated with platelet-rich plasma (PRP) (a), the epidermis was perfectly reconstructed with marked keratinization. The dermis showed well-ordered granulation tissue (dense and oriented collagen fibers) and reappearance of hair follicles. In the group of wounds treated with honey (c), healing of all wounds, but the organization of collagen fibers in the dermis seemed less organized compared to wounds in the PRP group. On the $28^{\text {th }}$ day after surgery, perfect healing of the wounds treated with PRP (d), with excellent reepithelialization, organized dermis exhibits better oriented collagen fibers in comparison with the other groups. Healing was completed in the group treated with honey (e), but the epidermis showed desquamation with poor keratinization. Poor healing of wounds in the control group (f), delayed in most animals treated with saline solution and appearance of pronounced fibrosis at the site of the injury. 
suffering from chronic diseases and resistant to conventional treatments.In contrast, in recent decades, there has been a resurgence in the clinical use of honey as a topical treatment for skin wounds. A great deal of experimental evidence supports this resurgence, showing that honey debrides wounds, kills bacteria, penetrates biofilm, lowers wound $\mathrm{pH}$, reduces chronic inflammation, and promotes fibroblast infiltration [17].

From these results, the topical use of either PRP or honey when managing skin wounds is strongly recommended. Researchers have incorporated honey into tissue engineered models, including electrospun meshes, cryogels, and hydrogels, with varying degrees of success $[17,18]$. This study was designed to continue the investigation of the biological effects of PRP. The main objective of this study is to compare the main histopathological changes associated with the topical administration of PRP and honey on skin wounds experimentally produced in sheep.

In this study, the wounds were macroscopically and microscopically examined to follow the progress of healing. The semi-quantitative evaluation of the histopathological scores obtained revealed significant differences in several healing parameters.

Three days after surgery, a significant difference in the number of PMNLs was observed with the group of animals treated with PRP having the highest number of PMNLs. At this stage in the healing process, this comparative study showed that honey did not alleviate inflammation compared with PRP. This result agrees with the results of several studies. Anitua et al. [19] and Kaux et al. [20] have reported that PRP promotes leukocyte diapedesis in the wound bed and accentuates the power of cell differentiation of monocytes into phagocytic ones. Conversely, for honey, we found that it has not reduced inflammation as suggested by Abuharfeil et al. [21] and Yaghoobi et al. [22]. These authors have reported that honey has absorbent and moisturizing properties that can reduce wound edema and can act on stages of the healing process through early inflammation and rapid proliferation.

Seven days after surgery, in the group of wounds treated with PRP, we recorded significant differences in reepithelialization and fibroblast infiltration. According to Pizzicannella et al. [23], these could be due to growth factors released by platelets that stimulate the surrounding cells. This three-dimensional scaffolding provided by PRP is rapidly colonized by fibroblasts, which generate components of the ECM and stimulate the systematic reconstruction of skin tissue $[24,25]$. This is the proliferative phase, known as the granulation phase. It is marked by significant angiogenesis, accelerated fibroplasia and deposition of ECM, all leading to reepithelialization. The results of this study may lead to a better understanding of the role of PRP as a biostimulator in treating skin wounds [26]. Taken together, PRP represents a positive therapeutic option for damaged cells and tissue regeneration.
Fourteen days after surgery, the synthesis and organization of collagen fibers were significantly improved in the groups of wounds treated with PRP and honey. Our results confirmed the usefulness of the therapeutic use of PRP and honey in managing skin wounds. These are clearly evident in Figure-4a. Nevertheless, despite the large number of studies that confirm the effectiveness of honey in healing skin wounds, in this study, the group of wounds treated with honey was not better than the group treated with PRP. Takzaree et al. [27] have reported faster healing and greater reduction of the wound area following the use of honey. In this study, honey promoted the repair of skin wounds in sheep and made the granulation tissue hypertrophic by increasing the synthesis of collagen; however, the latter does not allow the correct course of the remodeling and redesigning processes (Figure-5b).

Twenty-eight days after surgery, healing of all wounds with esthetic variations was quite evident in the micrograph shown in Figures-6d-f. Perfect healing was observed in wounds treated with PRP(Figure-6d), characterized by a similar reconstitution of the skin to normal appearance with well-organized dermis and numerous hair follicles. Our results agree with those of other similar studies $[19,25,28]$. These studies have reported positive results on the use of PRP as a future cell therapy option for alopecia. According to Miao et al. [29] and Xiao et al. [28], PRP behaved as an optimal three-dimensional scaffold that induces the cellular expression of versican, beta-catenin, and alkaline phosphatase necessary for hair growth by inducing the differentiation of follicular stem cells of the dermal papilla and prolonging the anagen phase of the hair growth cycle. In addition, the anti-apoptotic effects of activated PRP have been suggested as one of the main factors contributing to the stimulation of hair growth and increase in the perifollicular vascular plexus through increased levels of vascular endothelial growth factor and platelet-derived growth factor, which promote hair growth and angiogenesis [30].

Finally, the results of this experimental study confirm the effectiveness of PRP as a promising remedy in managing skin wounds in sheep. These results should be accepted as preliminary, and the platelet concentration remains uncertain due to interindividual variability and the particular factors influencing each case.

\section{Conclusion}

Wound healing is a continuous and complex process that is characterized by three overlapping phases: The inflammatory, proliferative, and remodeling phases. This process is a series of complex and beautifully orchestrated interactions of cells and mediators, which can be affected by various internal and environmental factors. In this study, topical administration of PRP is a promising method for healing skin wounds in sheep, but the application of honey did not lead to 
better results. Further in-depth studies to refine a standard preparation protocol for PRP and determine an ideal concentration of PRP to standardize the scientific literature are recommended.

\section{Authors' Contributions}

DA: Conception and design of the study, realization of the experiment, writing and revision of the manuscript. DO: Data analysis and interpretation, manuscript drafting. Both authors read and approved the final manuscript.

\section{Acknowledgments}

The authors are thankful to the staff of the Department of Veterinary Medicine, University of Batna 1, Batna, Algeria for automaton, microtome, formaldehyde and hematoxylin. The authors are grateful to the technical staff of the University Hospital of Batna (Histopathology Department), Algeria, to provide all the necessary facilities for performing the histopathological study. This research was funded by the University of Batna 1, Algeria (Grant No. F01320140031 01/01/2015).

\section{Competing Interests} interests.

The authors declare that they have no competing

\section{Publisher's Note}

Veterinary World remains neutral with regard to jurisdictional claims in published institutional affiliation.

\section{References}

1. Woodley, D.T., Chen, J.D., Kim, J.P., Sarret, Y., Iwasaki, T., Kim, Y.H. and O'Keefe, E.J. (1993) Re-epithelialization: Human keratinocyte locomotion. Dermatol. Clin., 11(4): 641-646.

2. Addis, R., Cruciani, S., Santaniello, S., Bellu, E., Sarais, G., Ventura, C., Maioli, M. and Pintore, G. (2020) Fibroblast proliferation and migration in wound healing by phytochemicals: Evidence for a novel synergic outcome. Int. J. Med. Sci., 17(8): 1030-1042.

3. Ozcelikkale, A., Dutton, J.C., Grinnell, F. and Ha, B. (2017) Effects of dynamic matrix remodelling on en masse migration of fibroblasts on collagen matrices. J. R. Soc. Interface, 14(135): 20170287

4. Johnson, B.Z., Stevenson, A.W., Prêle, C.M., Fear, M.W. and Wood, F.M. (2020) The role of IL-6 in skin fibrosis and cutaneous wound healing. Biomedicines, 8(5): 101.

5. Won, J.K., Young, C.N., Bum, S.S., Hyeon, A.K., Woo, H.H., Gum, H.A., Choi, H.C. and Seo, U.L. (2013) The effects of topical agent (Kelo-Cote or contractubex) massage on the thickness of post-burn scar tissue formed in rats. Arch Plast Surg., 40(6): 697-704.

6. Dohan, S., Dohan, A., Choukroun, J., Diss, A., Simonpieri, A., Girard, M.O. and Dohan, D. (2005) Autologous platelet concentrates for topical use. EMCODO, 1(2): 141-180.

7. Daikh, B. and Benoune, O. (2018) the effectiveness of platelet-rich plasma on the skin wound healingprocess: A comparative experimental study in sheep. Vet. World, 11(6): 800-808.

8. Martinotti, S. and Ranzato, E. (2018) Honey, wound repair and regenerative medicine. J. Funct. Biomater, 9(2): 34.
9. Salman, H., Kashmoola, M.A., Al-Waiz, M.M. and Al-Sandooq, T.A. (2008) Differences between low level laser therapy and triamcinolone acetonide kenalog on healing of recurrent aphthous ulceration. Ann. Coll. Med. Mosul, 34(1): 35-41.

10. Santuzzi, C.H., Buss, H.F., Pedrosa, D.F., Freire, M.O., Nogueira, B.V. and Gonçalves, W.L. (2011) Combined use of low level laser therapy and cyclooxygenase-2 selective inhibition on skin incisional wound reepithelialization in mice: A preclinical study. An. Bras. Dermatol., 86(2): 278-283.

11. Carneiro, M.O., Barbieri1, C.H. and Neto, J.B. (2013) Platelet-rich plasma gel promotes regeneration of articular cartilage in knees of sheep's. Acta Ortop. Bras., 21(2): 80-86.

12. Ibrahim, Z.A.L., El-Tatawy, R.A., El-Samongy, M.A. and Ali, D.A.M. (2015) Comparison between the efficacy and safety of platelet-rich plasma vs. microdermabrasion in the treatment of striae distensae: Clinical and histopathological study. J. Cosmet. Dermatol., 14(4): 336-346.

13. Alishahi, K.M., Mofidpoor, H. and Alishahi, M.A.K. (2014) Histopathological evaluation of the effect of platelet-rich fibrin on canine cutaneous incisional wound healing. Int. J. Agro Vet. Med. Sci., 8(5): 134-141.

14. AL-Bayati, A.H., Al-Asadi R.N., Mahdi A.K. and Al-Falahi, N.H. (2013) Effects of autologous platelets rich plasma on full-thickness cutaneous wounds healing in goats. Int. J. Anim. Vet. Adv., 5(6): 233-239.

15. Vidinsky, B., Gal, P., Toporcer, T., Longauer, F., Lenhardt, A., Bobrov N. and Sabo, J. (2006) Histological study of the first seven days of skin wound healing in rats. Acta Vet., 75(2): 197-202.

16. Kilík, R., Lakyová, L., Sabo, J., Kruzliak, P., Lacjaková, K., Vasilenko, T., Vidová, M., Longauer, F. and Radoňak, J. (2014) Effect of equal daily doses achieved by different power densities of low-level laser therapy at $635 \mathrm{~nm}$ on open skin wound healing in normal and diabetic rats. Biomed. Res. Int., 2014: 269253.

17. Benjamin, A.M. and Bowlin, G.L. (2018) Honey-based templates in wound healing and tissue engineering. Bioengineering., 5(6): 46.

18. Molan, P.C. (2011) The evidence and the rationale for the use of honey as wound dressing. Wound Pract. Res., 19(4): 204-220.

19. Anitua, E., Pino, A., Jaen, P. and Navarro, M.R. (2018) Platelet rich plasma for the management of hair loss: Better alone or in combination? Int. J. Oral Maxillofac. Pathol., 14(3): 529-535.

20. Kaux J.F., Drion P., Croisier J.L., Colige, A., Libertiaux, V., Gothot, A. and Crielaard, J.M. (2014) Plasma rich in platelets and tendonous lesions. Rev. Med. Liege., 69: 72-77.

21. Abuharfeil, N., Al-Oran, R. and Abo-Shehada, M. (1999) The effect of bee honey on the proliferative activity of human B-and T-lymphocytes and the activity of phagocytes. Food Agric. Immunol., 11(2): 169-177.

22. Yaghoobi, R., Kazerouni, A. and Kazerouni, O. (2013) Evidence for clinical use of honey in wound healing as an anti-bacterial, anti-inflammatory anti-oxidant and anti-viral agent: A review. Jundishapur J. Nat. Pharm. Prod., 8(3): 100-104.

23. Pizzicannella, J., Gugliandolo, A., Orsini, T., Fontana, A., Ventrella, A., Mazzon, E., Bramanti, P., Diomede, F. and Trubiani, O. (2019) Engineered extracellular vesicles from human periodontal-ligament stem cells increase VEGF/ VEGFR2 expression during bone regeneration. Front. Physiol., 10(4): 512.

24. Myers, S.R., Partha, V.N., Soranzo, C, Price, R.D. and Navsaria, H.A. (2007) Hyalomatrix: A temporary epidermal barrier, hyaluronan delivery, and neodermis induction system for keratinocyte stem cell therapy. Tissue Eng., 13(11): 2733-2741.

25. Gentile, P. and Garcovich, S. (2020) Systematic review of 
platelet-rich plasma use in androgenetic alopecia compared with minoxidilfi, finasteridefi, and adult stem cell-based therapy. Int. J. Mol. Sci., 8(4): 2702.

26. Rossi, S., Mori, M., Vigani, B., Bonferoni, M.C., Sandri, G., Riva, F. and Caramella, C.F.A. (2018) Novel dressing for the combined delivery of platelet lysate and vancomycin hydrochloride to chronic skin ulcers: Hyaluronic acid particles in alginate matrices. Eur. J. Pharm. Sci., 118(6): 87-95.

27. Takzare, N., Hassanzadeh, G., Rouini, M.R., Manayi, A., Hadjiakhondi, A. and Zolbin, M.M. (2017) Evaluation of the effects of local application of thyme honey in open cutaneous wound healing. Iran. J. Public Health, 46(4): $545-551$.
28. Xiao, S.E., Miao, Y., Wang, J., Jiang, W., Zhe-Xiang, F.D., Liu, X.M. and Hu, Z.Q. (2017) As a carrier-transporter for hair follicle reconstitution, platelet-rich plasma promotes proliferation and induction of mouse dermal papilla cells. Sci. Rep., 7: 1125.

29. Miao, Y.M.D., Sun, Y.B., Sun, X.N., Du, B.J., Jiang, J.D. and Hu, Z.Q. (2013) Promotional effect of platelet-rich plasma on hair follicle reconstitution in vivo. Dermatol. Surg., 39(12): 1868-1876.

30. Gkini, M.A., Kouskoukis, A.E., ripsianis, G., Rigopoulos, D. and Kouskoukis, K. (2014) Study of platelet-rich plasma injections in the treatment of androgenetic alopecia through an one-year period. J. Cutan. Aesthet. Surg., 7(4): 213-219.

$* * * * * * * *$ 